\title{
A case of ovarian Sertoli-Leydig cell tumor with multiple endocrine gland involvement
}

\author{
Lakshmi Manjeera, Neetha Vyas M*, Supriya Rai
}

\author{
Department of Obstetrics \& Gynecology, K.S. Hegde Medical Academy, Nitte University, Deralakatte, Mangalore, \\ Karnataka, India
}

Received: 18 November 2012

Accepted: 12 December 2012

\author{
*Correspondence: \\ Dr. Neetha Vyas M, \\ E-mail: nvyas_21@yahoo.com
}

\begin{abstract}
Sertoli-Leydig Cell Tumors (SLCT) comprises an uncommon and heterogeneous group of ovarian neoplasms within sex-cord stromal category. Retiform type accounts to about $10-15 \%$ of all SLCTs and they are less androgenic than other variants. We present to you a 20 year old lady who came to us with features of virilisation and abdominal mass. Intra-operatively, mass arose from left ovary. Left salpingo-oophorectomy was done. Histopathological diagnosis was SLCT with retiform pattern and with a foci of heterologous elements. Interestingly, patient had undergone hemithyroidectomy at the age of 9 for thyroid adenoma. As a part of pre-operative work up, computed tomography revealed an incidental finding of adrenal adenoma but overnight dexamethasone suppression test was negative. There have been reports of association of thyroid conditions with SLCT but here we are reporting association of two endocrine glands (thyroid and adrenal) in the same patient.
\end{abstract}

Keywords: Sertoli-Leydig cell tumor, virilisation, Thyroid, Adrenal gland

\section{INTRODUCTION}

Although Sertoli-Leydig Cell Tumor (SLCT) is the most common androgen producing ovarian tumors, they just represent less than $0.5 \%$ of all ovarian neoplasms. ${ }^{1}$ Of the subtypes, ovarian SLCT with retiform pattern accounts for less than $0.2 \%$ of all ovarian neoplasm and less than $4 \%$ of ovarian tumors less than 20 years of age. ${ }^{2}$ Retiform variant account for about $10-15 \%$ of all SLCTs. ${ }^{2}$ They are named so because the growth pattern resemble rete testis in histopathological examination.

\section{CASE REPORT}

A 20 year old lady presented to us with a history of secondary amenorrhea since 1 year. Following that, she noticed excessive hair growth on the face, flattening of breasts, hoarseness of voice and weight loss which was progressive from the last 6 months. Patient had undergone hemithyroidectomy at the age of 9 for thyroid adenoma. No significant family history was noted. Her general examination revealed thyroid swelling, bilateral flat breast, Hirsutism. On abdominal examination, a mobile mass of $10 \times 10 \mathrm{~cm}$ with variable consistency was noted. External genitalia showed enlarged clitoris of about $3 \mathrm{~cm}$ long.

An ultrasound and computed tomography (CT) showed left ovarian mass of 10x10 cm with solid and cystic areas. There was minimal ascites. A small tumor on the lateral limb of left adrenal gland of 9x12 mm mostly likely adenoma was seen in CT. A hormonal profile in blood indicated excessive androgenic activity in the form of elevated testosterone levels $1.58 \mathrm{ng} / \mathrm{ml}$ (normal range: $0.2-1.2 \mathrm{ng} / \mathrm{ml}$ ). However dehydroepiandrosterone sulfate (DHEAS), Ca-125 and alphafetoprotein (AFP) were found to be normal. Thyroid profile was normal. As an adrenal tumor was found, overnight dexamethasone suppression test was done and found to be normal ruling out adrenal origin of androgen. Staging laparotomy was done. Ascitic fluid was sent for cytology. A left ovarian tumor of $10 \times 11 \mathrm{~cm}$ was noted. The other ovary appeared normal. There were no peritoneal deposits and paraarotic lymph nodes were not enlarged. As patient was young left salpingo-oophorectomy with infra-colic omentectomy 
was done. Post-operative period was uneventful. Histopathology was suggestive of Sertoli-Leydig cell tumor, retiform type (Figure 1) with intermediate differentiation and a foci of heterologous elements (cysts with mucinous epithelium). Cytology report of ascitic fluid showed cells suggestive of SLCT. So finally a diagnosis of stage IC Sertoli-Leydig cell tumor was made. After removal of the tumor, serum testosterone levels dropped back to normal. We had detailed discussion of various treatment options with patient. With her consent she received 4 cycles of BEP regimen. During the 1 year of follow up, patient has resumed her menstrual cycles with regression of her virilising symptoms.

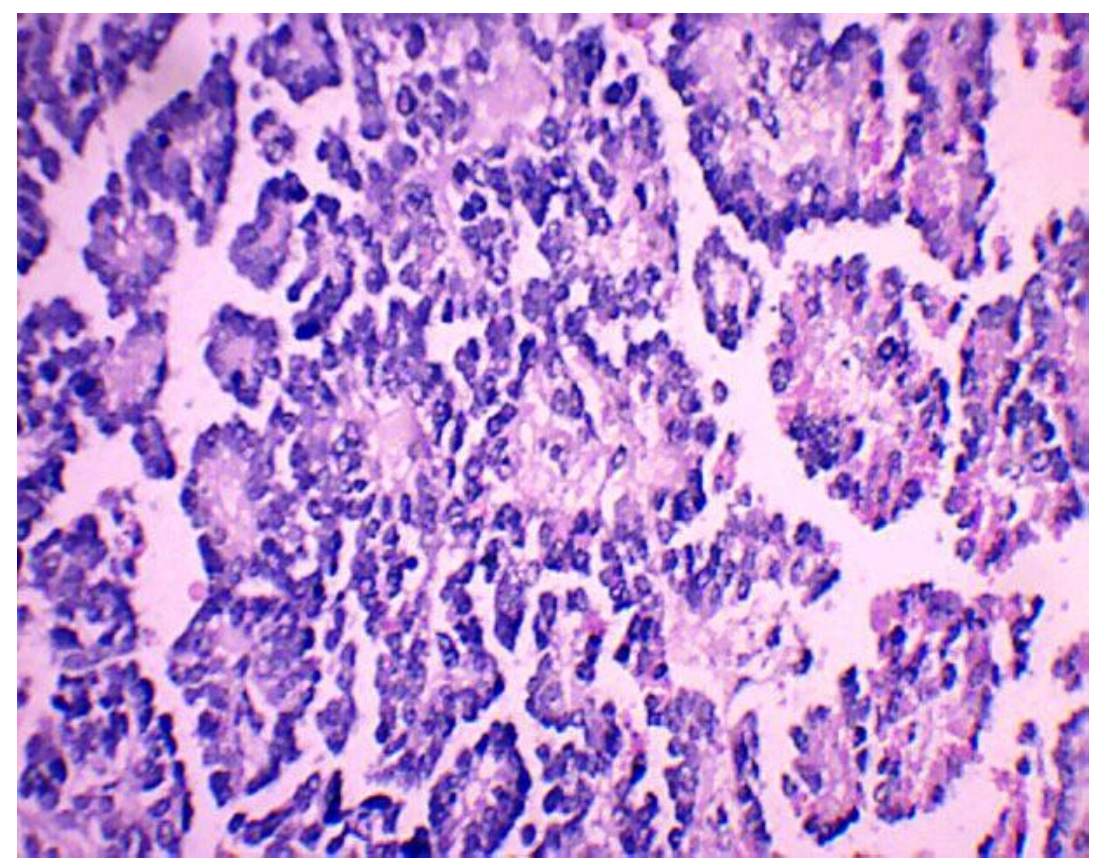

Figure 1: Microscopic picture showing Sertoli-Leydig cell tumor with retiform pattern.

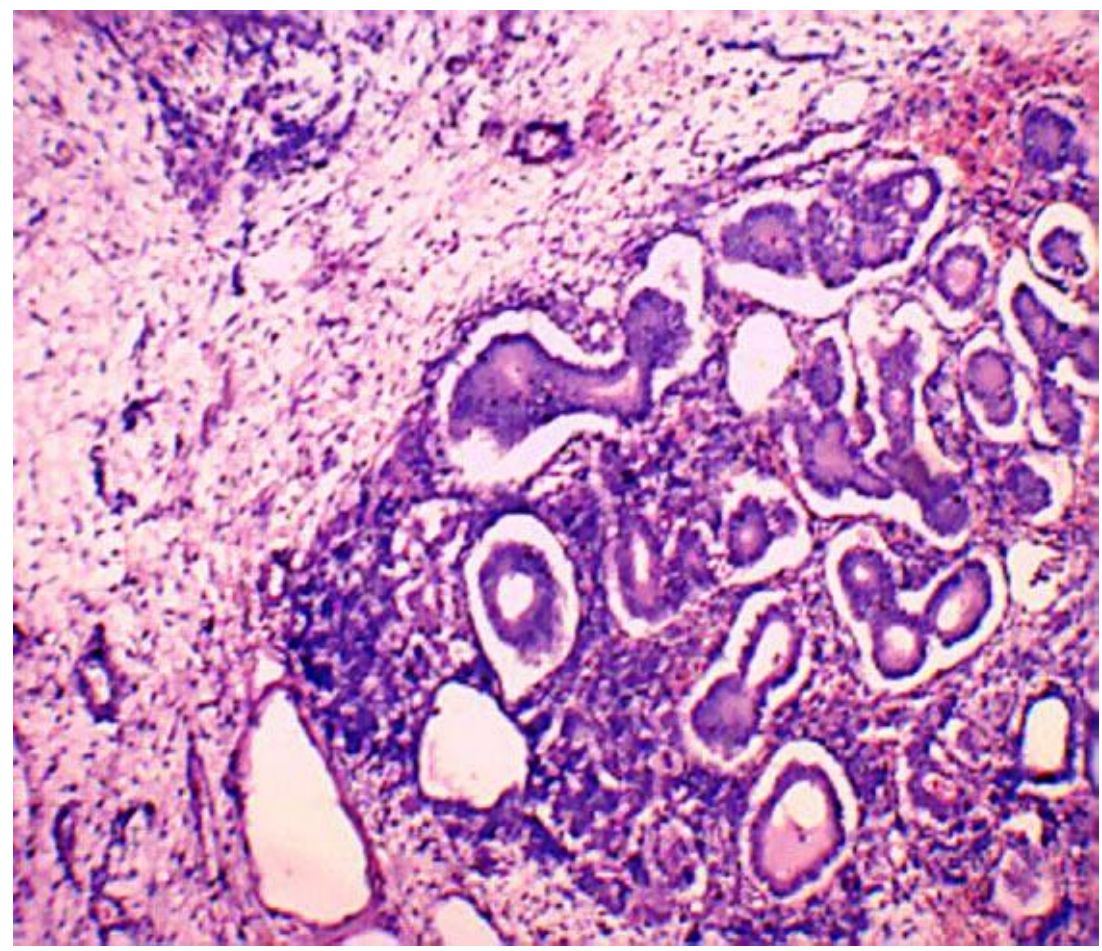

Figure 2: Microscopic picture showing intestinal type epithelium secreting mucin suggestive of presence of endodermal heterologous elements in Sertoli-Leydig cell tumor. 


\section{DISCUSSION}

Histologically, SLCTs are now classified as well differentiated, intermediate differentiated, poorly differentiated, heterologous and retiform type. Retiform SLCT comprise $10-15 \%$ of all SLCT. These are encountered in tumors with intermediate differentiated, poorly differentiated, heterologous elements. The clinical profile of this rare variant includes early presentation (1st decade) and a low incidence of virilisation (only 20\%) compared to other variants. ${ }^{1,3}$ Interestingly, our patient had gross features of virilisation like Hirsutism, hoarseness of voice and clitoromegaly. Retiform SLCTs are misinterpreted and difficult to diagnose. They are often mistaken for serous ovarian neoplasm, yolk sac tumor and malignant mixed mullerian tumor. ${ }^{4}$ Immunohistochemistry is useful in distinguishing retiform Sertoli-Leydig cell tumor from other tumors that they may resemble. ${ }^{4}$

Heterologous pattern occurs in $20 \%$ of SLCTs. These are of two types: endodermal elements and mesenchymal elements. Mucin-secreting epithelium like gastric or intestinal type represents endodermal elements. The mesenchymal elements are represented by immature cartilage and skeletal muscle. The SLCT with heterologous mesenchymal elements are poorly differentiated and carry poor prognosis in contrast to endodermal elements which typically are of intermediate differentiation. ${ }^{5}$ Our patient had mucinous epithelium like intestinal type suggestive of endodermal heterologous elements (Figure 2).

Many of the clinical manifestations are due to the degree of histologic differentiation and presence of a retiform pattern and/or heterologous elements. ${ }^{1}$ In premenopausal patient, oligomenorrhoea or amenorrhoea are frequent. If virilising signs are present menstrual irregularities are universal. Hirsutism occurs in virtually all SLCT patients. Deepening of voice is reported in $75 \%$ of virilised patients and clitoromegaly in $50 \%$. After resection of the tumor, androgenic manifestations resolve but virilising features like hirsutism, clitoromegaly and deepening of voice regress less reliably. SLCTs have been reported in association with other clinical entities like benign and malignant ovarian neoplasm and a few cases of prior sarcoma botryoides of the cervix has been reported. ${ }^{1,6}$ An unexpectedly high incidence of thyroid condition like benign thyroid nodules, carcinoma and multinodular goiter has also been reported. ${ }^{1,7}$ Even our patient had a thyroid adenoma for which she was operated earlier.
Added to this, we also found incidentally adrenal adenoma in her. Though association of thyroid gland involvement along with SLCT have been noticed and reported. But in this patient, even adrenal gland involvement was present. The background behind the association of SLCT with other endocrine gland needs more research and one should look out for it.

Though most of the retiform SLCTs are curable, but caution regarding prognosis is warranted. Recurrence is common. Bilateral involvement and extraovarian spread are rare and occur in $<5 \%$ of cases. ${ }^{3}$ So management of retiform SLCTs remains a challenge. Still it is inconclusive whether complete staging or post-operative adjuvant therapy is necessary.

\section{ACKNOWLEDGEMENTS}

We would like to thank Department of Pathology of K.S. Hegde Medical Academy, Mangalore for guiding us regarding histopathological diagnosis of the disease.

\section{REFERENCES}

1. Young RH, Scully RE. Ovarian Sertoli-Leydig cell tumors. A clinicopathological analysis of 207 cases. Am J Surg Pathol 1985;9:543-69.

2. Young RH, Scully RE. Ovarian Sertoli-Leydig cell tumor with a retiform pattern: A problem in histopathologic diagnosis. A report of 25 cases. Am J Surg Pathol 1983;7:755-71.

3. Kristine M, Zanotti MD. The clinical manifestations and diagnosis of ovarian Sertoli-Leydig cell tumors of the ovary. CME J Gynecol Oncol 2002;7:129-33.

4. Mooney EE, Nogales FF, Bergeron C, Tavassoli FA. Retiform Sertoli-Leydig cell tumors: clinical, morphological and immunohistochemical findings. Histopathology 2002;41:110-7.

5. Tandon R, Goel P, Saha PK, Takkar N, Punia RP. A rare ovarian tumor - Sertoli-Leydig cell tumor with heterologous element. MedGenMed 2007;9:44-47.

6. Persechini ML, Motton S, Leguevaque P, Donadille F, Escourrou G, Vierasu B, et al. Virilising ovarian tumor: a case associating a Sertoli-Leydig cell tumor and Brenner tumor. Gynecol Endocrinol 2011;27:345-50.

7. Poiana C, Virtej I, Carsote M, Banceanu G, Sajin M, Stanescu B, et al. Virilising Sertoli-Leydig Cell Tumor associated with thyroid papillary carcinoma: case report and general considerations. Gynecol Endocrinol. 2010;26:617-622.

DOI: $10.5455 / 2320-1770 . \mathrm{ijr} \operatorname{cog} 000612$

Cite this article as: Manjeera L, Neetha VM, Rai S.

A case of ovarian Sertoli-Leydig cell tumor with multiple endocrine gland involvement. Int J Reprod Contracept Obstet Gynecol 2012;1:55-7. 